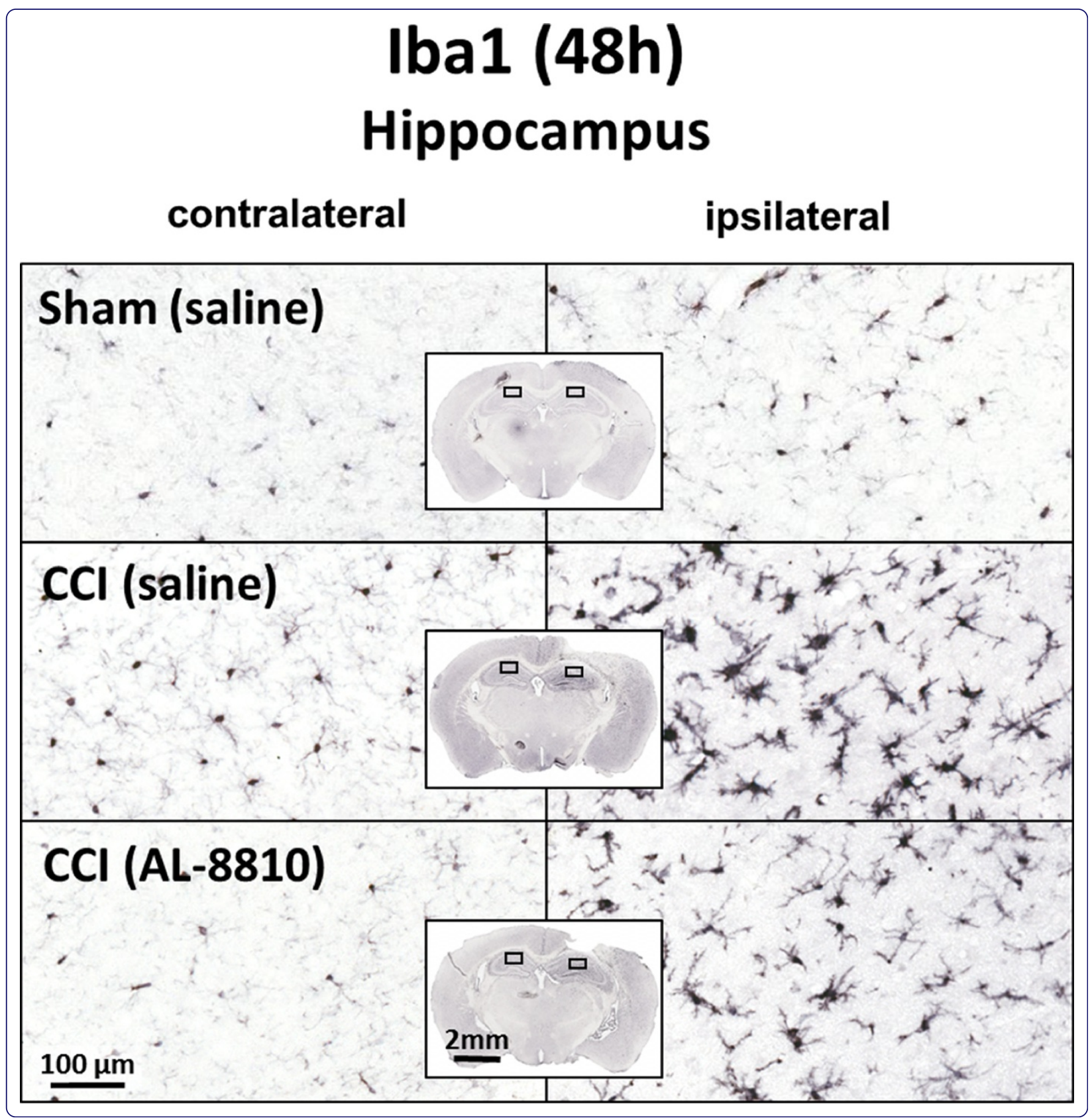

Prostaglandin $\mathrm{F}_{2 a}$ FP receptor antagonist improves outcomes after experimental traumatic brain injury

Glushakov et al. 


\title{
RESEARCH
}

Open Access

\section{Prostaglandin $\mathrm{F}_{2 a}$ FP receptor antagonist improves outcomes after experimental traumatic brain injury}

\author{
Alexander V Glushakov ${ }^{1}$, Sean W Robbins' ${ }^{1}$ Connor L Bracy ${ }^{1}$, Shuh Narumiya ${ }^{2}$ and Sylvain Doré 1,3* $^{*}$
}

\begin{abstract}
Background: Injuries to the brain promote upregulation of prostaglandins, notably the proinflammatory PGF $2 a$, and overactivation of their cognate G-protein-coupled FP receptor, which could exacerbate neuronal damage. Our study is focused on investigation of the FP receptor as a target for novel neuroprotective drugs in a preclinical animal traumatic brain injury (TBI) model.

Methods: Accordingly, the effects of acute intraperitoneal post-treatment with selective FP antagonist AL-8810 were studied in wildtype (WT) and FP receptor knockout $\left(\mathrm{FP}^{-/-}\right)$mice after controlled cortical impact (CCl). Neurological impairments were evaluated using neurological deficit scores (NDS) and the grip strength test. Cortical lesions and overall brain pathology were assessed using immunohistochemistry.

Results: Morphological analyses of cerebral vasculature and anastomoses revealed no differences between WT and $\mathrm{FP}^{-/-}$mice. $\mathrm{CCl}$ produced cortical lesions characterized by cavitation, neuronal loss, and hematoma with a volume of $20.0 \pm 1.0 \mathrm{~mm}^{3}$ and significant hippocampal swelling (146.5 $\pm 7.4 \%$ of contralateral) compared with sham $(P<0.05)$. Post-treatment with AL-8810 (1 to $10 \mathrm{mg} / \mathrm{kg}$ ) had no significant effect on cortical lesions, which suggests the irreversible effect of primary CCl injury, but significantly reduced hippocampal swelling to a size not significantly different from the sham group. Post-treatment with AL-8810 at a dose of $10 \mathrm{mg} / \mathrm{kg}$ significantly improved NDS at 24 and 48 hours after $C C I(P<0.001$ and $P<0.01$, respectively). In the AL-8810 group, CCl-induced decrease in grip strength was three-fold $(2.93 \pm 1.71)$ less and significantly different than in the saline-treated group. The $\mathrm{FP}^{-/-}$mice had significantly less hippocampal swelling, but not NDS, compared with WT mice. In addition, immunohistochemistry showed that pharmacologic blockade and genetic deletion of FP receptor led to attenuation of CCl-induced gliosis and microglial activation in selected brain regions.
\end{abstract}

Conclusion: This study provides, for the first time, demonstration of the unique role of the FP receptor as a potential target for disease-modifying CNS drugs for treatment of acute traumatic injury.

Keywords: AL-8810, Controlled cortical impact, Glial fibrillary astrocytic protein, G-protein-coupled receptors, Knockout mice, Prostaglandin F2a receptor, Traumatic brain injury

\footnotetext{
*Correspondence: sdore@ufl.edu

'Department of Anesthesiology, University of Florida College of Medicine, PO

Box 100159, Gainesville, FL 32610, USA

${ }^{3}$ Departments of Neuroscience, Neurology, Psychiatry, and Center for

Translational Research in Neurodegenerative Disease, University of Florida

College of Medicine, 1275 Center Drive, Biomed Sci J493, PO Box 100159,

Gainesville, FL 32610, USA

Full list of author information is available at the end of the article
} 


\section{Background}

Traumatic brain injury (TBI) is among the major causes of death and disability in the United States and current treatment is limited to supportive care. TBI is a complex disorder including four main pathological sequelae: contusions, diffuse axonal injury, hematoma, and subarachnoid hemorrhage causing secondary biochemical and metabolic changes that contribute to neuronal death [1]. Secondary brain injury involving excitotoxicity, oxidative stress, and neuroinflammation and edema plays a key role in the neurological outcome of TBI survivors [2]. Although the secondary injury following TBI is potentially treatable, there is no effective treatment currently available, and the discovery of new targets for TBI therapeutics remains critical. A few anti-inflammatory pathways are currently considered as a promising approach in TBI [3]. Furthermore, most of the therapeutic agents currently considered for TBI translation exhibit direct or indirect anti-inflammatory actions [4]. A growing body of experimental and clinical evidence suggests that the inducible cyclooxygenase-2 (COX-2) and prostaglandin synthetase enzymes play an important role in the neuroinflammatory cascades associated with neurotoxicity and neuronal damage during brain insults [5-8]. Increased COX-2 immunoreactivity has been demonstrated in microglia and neurons of the ischemic neonatal and adult human brain [9-11]. In addition, COX-2 upregulation has been reported in the cortex and hippocampus after experimental TBI, and this upregulation was associated with neuronal death [12-16]. Experimental evidence also has demonstrated that brain trauma causes an increased release of arachidonic acid, a COX-2 substrate involved in prostaglandin production $[17,18]$. Although COX-2 inhibition could be beneficial in TBI [12,14-16,19], clinical application of COX-2 inhibitors might be limited because of cardiovascular side effects [20]. Further studies on the downstream effectors of COX-2, such as prostaglandins and their respective receptors, have been previously been conducted and suggested that the certain prostaglandin receptor antagonists could be used as an alternative to COX-2 inhibitors [8]. Activation of several subtypes of prostaglandin receptors leads to increased intracellular calcium and neurotoxicity. The effects of $\mathrm{PGF}_{2 \alpha}$ are mediated via activation of its specific G-protein-coupled receptor, the FP receptor, and would result in neuronal intracellular calcium overload [21]. The roles of COX-2 and some prostaglandins are understood in stroke models $[7,8,21,22]$; however, the effect of $\mathrm{PGF}_{2 \alpha}$ and its FP receptor are not understood in TBI.

With the known physiological role of the FP receptor in calcium signaling $[6,21]$, we hypothesized that changes in levels of $\mathrm{PGF}_{2 \alpha}$, due to increased COX-2 activity, and subsequent FP receptor overactivation may contribute to excitotoxic, hypoxic, and hemorrhagic damage [7]. Hence, our study was focused on the investigation of the FP receptor as a target for TBI drugs using its selective antagonist and FP receptor knockout $\left(\mathrm{FP}^{-1-}\right)$ mice in a controlled cortical impact (CCI) model. Based on our preliminary data indicating that $\mathrm{FP}^{-/-}$mice have significantly reduced infarct volume following stroke $[21,22]$, we have tested whether genetic deletion of the FP receptor or its pharmacologic blockade with the selective antagonist AL-8810 [23] would limit brain damage and neurological outcome following brain trauma.

\section{Methods \\ Animals}

All animal protocols were approved by the University of Florida Animal Care and Use Committee. A total of 83 male wildtype (WT) and 20 male FP receptor knockout $\left(\mathrm{FP}^{-/-}\right) \mathrm{C} 57 \mathrm{BL} / 6$ mice aged $2.0 \pm 1.1$ and $4.2 \pm 1.5$ months, respectively, was used. The mean body weight of WT and $\mathrm{FP}^{-/-}$mice used for CCI was $23.3 \pm 1.5(\mathrm{n}=75)$ and $21.8 \pm$ $3.9 \mathrm{~g}(\mathrm{n}=17)$, respectively.

\section{$\mathrm{CCl}$ procedures}

CCI in mice was produced using PCI3000 PinPoint Precision Cortical Impactor (Hatteras Instruments, Cary, NC, USA) and a stereotaxic apparatus (David Kopf Instruments, Tujunga, CA, USA). Prior to all procedures, anesthesia was induced with $4 \%$ isoflurane in a $25 \%$ oxygen-in-air mixture. During all surgical procedures, mice were maintained on $2 \%$ isoflurane anesthesia via nose cone, and body temperatures were monitored using a rectal probe and were maintained with a controlled heating pad (Fine Science Tools, Vancouver, BC, Canada). After the skull was exposed with a central skin incision and soft tissue was removed with a cotton tip, a circular craniotomy of approximately $4 \mathrm{~mm}$ in diameter was made in the middle of the right parietal bone, about $0.5 \mathrm{~mm}$ from sagittal, coronal, and lambdoid sutures, leaving the dura intact under visual control using an Olympus SZ61 dissecting microscope (Olympus Corporation, Tokyo, Japan). The CCI parameters were as follows: impact tip diameter $3 \mathrm{~mm}$, velocity $3 \mathrm{~m} / \mathrm{s}$, compression time $100 \mathrm{~ms}$, and a compression distance of $1 \mathrm{~mm}$. These parameters allow to produce experimental TBI of mild-to-moderate severity based on anatomical and neurobehavioral outcomes [24]. Sham mice underwent craniotomy only. After surgical procedures, the incision was closed using Reflex 7 skin closure system (CellPoint Scientific, Inc., Gaithersburg, MD, USA), each mouse received an intraperitoneal injection of warm saline to prevent dehydration, and the mice were transferred to a temperature-controlled recovery chamber for at least one hour. 


\section{Drug treatments}

In single regiment groups, AL-8810 (Cayman Chemical Co., Ann Arbor, MI, USA) was injected intraperitoneally after completion of all surgical procedures at two doses: 1 and $10 \mathrm{mg} / \mathrm{kg}$. The animals with repeated treatment received three injections of AL-8810 at $10 \mathrm{mg} / \mathrm{kg}$ each. AL-8810 injections were done directly after surgery and at 24 and 48 hours. To perform the second and third injections, mice were briefly anesthetized with isoflurane to avoid potential injury to the surgery site due to handling. AL-8810 was dissolved in dimethyl sulfoxide at a concentration of $25 \mathrm{mg} / \mathrm{mL}$, aliquoted, and stored at $-20^{\circ} \mathrm{C}$. Solutions for AL-8810 injection 25 or $250 \mu \mathrm{g} / \mathrm{mL}$ for AL-8810 doses of 1 and $10 \mathrm{mg} / \mathrm{kg}$, respectively, were prepared in saline immediately before use.

\section{Neurological deficit scores (NDS)}

Neurological function was assessed using a comprehensive 24-point NDS, slightly modified from Clark and colleagues [25]. The assessment included six individual tests, and each test was scored from 0 for normal performance up to 4 points with increasing severity, as summarized in Table 1. The sum of scores from the individual tests was reported as the NDS. All scoring was performed at the time of test and was verified offline using video recordings. The NDS was assessed at least at 24 hours after termination of anesthesia in single and repeated drug- or saline-treatment groups. No detectable differences were observed between saline-treated sham groups with single and repeated treatments, indicating that brief anesthesia had no effect on NDS; thus, the NDS data from saline-treated treated mice that underwent CCI were pooled together.

\section{Grip strength test}

Forelimb strength measurements in mice were carried out using the Animal Grip Strength System (San Diego Instruments, San Diego, CA, USA). The mouse was placed over the grid by the tail so that its forepaws were allowed to grasp the steel bar and it was then pulled backward until the grip was released. Each test consisted of three consecutive trials. Between trials, each mouse was allowed to rest for one minute. The data were reported as the average value of maximal force recorded before the mouse released the bar. Baseline grip strength values were obtained in each animal one day before CCI or sham procedure.

\section{Histological procedures and analyses}

Mice were euthanized and transcardially perfused with $4 \%$ paraformaldehyde in PBS. Brains were removed, post-fixed with the perfusion solution, and incubated for at least 24 hours in $30 \%$ sucrose/PBS solution. A series of eight $30-\mu \mathrm{m}$ thick coronal sections were obtained throughout the entire brain and processed for histological analysis. To quantitate brain pathology, cresyl violet staining was used. Cortical infarct volume was quantified using a slightly modified procedure described elsewhere [26]. Briefly, cortical lesion volume was calculated from injured areas located and measured in eight brain sections spaced within $0.5 \mathrm{~mm}$ apart from the same animal. The lesions characterized by cavitation, neuronal loss, and hematoma. These cresyl violetstained slides were also used for assessment of hippocampal edema. Hippocampal swelling was quantified using three brain sections from the same slides between 1 and $2 \mathrm{~mm}$ posterior to the bregma, representing injured brain regions within midline of focal impact. The areas of hippocampi in each hemisphere were measured and presented as the mean ratio between values of ipsilateral to contralateral sides. Immunohistochemistry for ionized calcium-binding adapter protein 1 (Iba1) and glial fibrillary acidic protein (GFAP) immunohistochemistry were performed using polyclonal rabbit anti-Iba1 (1:1,000 dilution; Wako Bioproducts, Richmond, VA, USA) and anti-GFAP (1:2,000 dilution; DAKO, Carpinteria, CA, USA) primary antibodies, respectively, avidin-peroxidase-

Table 1 Neurological deficit scoring

\begin{tabular}{|c|c|c|c|c|c|c|}
\hline Test & $\begin{array}{l}\text { Body } \\
\text { symmetry }\end{array}$ & Gait & Circling behavior & Climbing & Front limb symmetry & Compulsory circling \\
\hline Score & \multicolumn{3}{|c|}{$\begin{array}{l}\text { Mouse allowed to move freely on the } \\
\text { elevated open rectangular plain surface for } \\
\text { two to five minutes }\end{array}$} & $\begin{array}{l}\text { Mouse placed on the gripping } \\
\text { surface with } 45^{\circ} \text { angle for } \\
60 \text { seconds }\end{array}$ & $\begin{array}{l}\text { Mouse suspended by } \\
\text { tail for } 30 \text { seconds }\end{array}$ & $\begin{array}{l}\text { Mouse suspended by tail with } \\
\text { front limbs on bench for } \\
30 \text { seconds }\end{array}$ \\
\hline 0 & normal & normal & not present & normal & not present & not present \\
\hline 1 & $\begin{array}{l}\text { tilting on } \\
\text { one side }\end{array}$ & $\begin{array}{c}\text { stiff, } \\
\text { inflexible }\end{array}$ & $\begin{array}{l}\text { predominant one- } \\
\text { sided turns }\end{array}$ & climbs with strain & slight asymmetry & tendency to turn to one side \\
\hline 2 & $\begin{array}{l}\text { moderate } \\
\text { asymmetry }\end{array}$ & limping & $\begin{array}{l}\text { circles to one side } \\
\text { not constantly }\end{array}$ & holds on slope & marked asymmetry & circles to one side \\
\hline 3 & $\begin{array}{l}\text { prominent } \\
\text { asymmetry }\end{array}$ & trembling & $\begin{array}{l}\text { circles to one side } \\
\text { constantly }\end{array}$ & $\begin{array}{l}\text { slides down slope, unsuccessful } \\
\text { effort to prevent fall }\end{array}$ & prominent asymmetry & pivots to one side sluggishly \\
\hline 4 & $\begin{array}{l}\text { extreme } \\
\text { asymmetry }\end{array}$ & $\begin{array}{l}\text { does not } \\
\text { walk }\end{array}$ & $\begin{array}{l}\text { pivoting, swaying, } \\
\text { or no movement }\end{array}$ & $\begin{array}{l}\text { slides down immediately, no effort } \\
\text { to prevent fall }\end{array}$ & $\begin{array}{l}\text { slight asymmetry, no } \\
\text { body or limb } \\
\text { movement }\end{array}$ & does not advance \\
\hline
\end{tabular}


labeled biotin complex secondary antibodies (1:1,000 dilution; BA-500, Vector Laboratories, Burlingame, CA, USA), and Vectastain ABC and DAB SK-4100 kits (Vector Laboratories, Burlingame, CA, USA) according to the manufacturer's instructions. All slides were scanned using ScanScope CS (Aperio Technologies, Inc., Vista, CA, USA) and analyzed using ImageScope software (Aperio Technologies, Inc., Vista, CA, USA).

\section{Visualization of vasculature and analysis of anastomosis}

Mice were deeply anesthetized with a lethal dose of isoflurane and were perfused via the left ventricle with $5 \mathrm{~mL}$ of cold PBS, followed by $1 \mathrm{~mL}$ of black latex paint with flow rates not to exceed $1 \mathrm{~mL} / \mathrm{min}$. The brains were postfixed in $10 \%$ paraformaldehyde for 24 hours at $4^{\circ} \mathrm{C}$ prior to imaging of the dorsal cortical surface. Images of the dorsal surface were obtained using a desktop endoscope/ microscope. Anastomosis of the cortical surface was determined by tracing the distal branches of the anterior cerebral artery (ACA) and middle cerebral artery (MCA) to the point of anastomosis. The point of anastomosis was defined as the narrowest point along the vessel connecting the ACA and MCA, or halfway between the nearest branch points [27]. Each anastomosis was marked with a dot. All anastomoses were connected with a line to form the line of anastomosis. Next, the distance from the midline was determined by measuring, from the midline to the line of anastomosis, every millimeter from the frontal pole to the end of the cerebral cortices [28].

\section{Statistical analyses}

The statistical comparisons among multiple groups were done using one-way ANOVA followed by Tukey's multiple comparison test. Differences between two groups were determined by two-tailed paired or unpaired Student's $t$-tests. Normality assumption testing was performed using the Kolmogorov-Smirnov test. If data were nonparametric by nature (for example, data were already ordered according to qualitative ranks such as NDS), the Kruskal-Wallis ANOVA on ranks sum test was used to compare differences between multiple groups and the Wilcoxon rank sum test was used to compare differences between two groups to compare measurements before and after an intervention (that is, single and repeated drug treatments) in the same animals. Data are presented as the mean \pm standard error or mean \pm standard deviation and $P<0.05$ was considered as statistically significant [29].

\section{Results}

Effect of selective FP antagonist AL-8810 on the anatomical outcomes

To determine the effects of CCI in all experiments, the treated animals were compared with sham-operated animals that had undergone craniotomy only. To evaluate the FP receptor as a novel target, selective FP receptor antagonist AL-8810 was administered intraperitoneally within ten minutes after $\mathrm{CCI}$, as we previously did in ischemic stroke models [21,22].

To determine if the FP receptor blockade will improve short-term anatomical outcome following CCI, brain sections were analyzed 48 hours after surgery. Mice were randomly assigned to four groups: sham, CCI saline control, and two AL-8810 treatment groups with doses of 1 and $10 \mathrm{mg} / \mathrm{kg}$. At the 48-hour time point, CCI caused complex cortical lesions, including hematoma, decrease in cellular density in surrounding areas, and loss of cortical tissues referred to as cavitation. In saline-treated animals, CCI caused cortical injury with a relative volume of $20.0 \pm$ $1.0 \mathrm{~mm}^{3}$, whereas no detectable cortical injury was observed in sham animals. Acute post-treatment with AL8810 at both doses had no significant effect on cortical lesions, which suggests the irreversible effect of primary mechanical CCI injury. Also, AL-8810 did not cause any detectable changes in brain morphology in the sham animals ( $\mathrm{n}=3$, Additional file 1: Figure S1A). In addition to cortical injury, significant hippocampal swelling (146.5 \pm $7.4 \%$ of contralateral) was observed in all saline-treated $\mathrm{CCI}$ animals compared with sham $(P<0.05, \mathrm{n}=4)$. Posttreatment with AL-8810 at both doses reduced CCIinduced hippocampal swelling to levels not significantly different from the sham group (Figure 1, A and B). However, a significant difference between AL-8810- and salinetreated animals that underwent CCI was observed only at a dose of $10 \mathrm{mg} / \mathrm{kg}$. To test whether the beneficial effects of a single post-treatment with AL-8810 (10 mg/kg) following CCI would be sustained for extended time periods, anatomical assessments were performed ten days after injury. To test whether repeated AL-8810 treatment would have additional benefits, this compound was administered at a dose of $10 \mathrm{mg} / \mathrm{kg}$ three times in a separate group. In this treatment group, the first AL-8810 injection was administered post-CCI, as in the single treatment group, and then two additional injections were given once a day during the next two days. At this late time point in the CCI group, the lesions were characterized by structurally defined cortical cavitation (Figure 1, C and D) and the significant hippocampal swelling was still present, though it was less prominent compared with the 48-hour time point. Ten days after injury, hippocampal swelling in the CCI group had a value of $126.39 \pm 4.110(n=8)$ of the contralateral side and was significantly lower than the value at the 48-hour time point $(P<0.05$, Student independent $t$-test between two CCI groups). Posttreatment with AL-8810 using both treatment regiments showed a tendency to decrease the CCI-induced hippocampal swelling to levels not significantly different from the sham group; however, there was no significant difference between single and repeated treatments or 
A

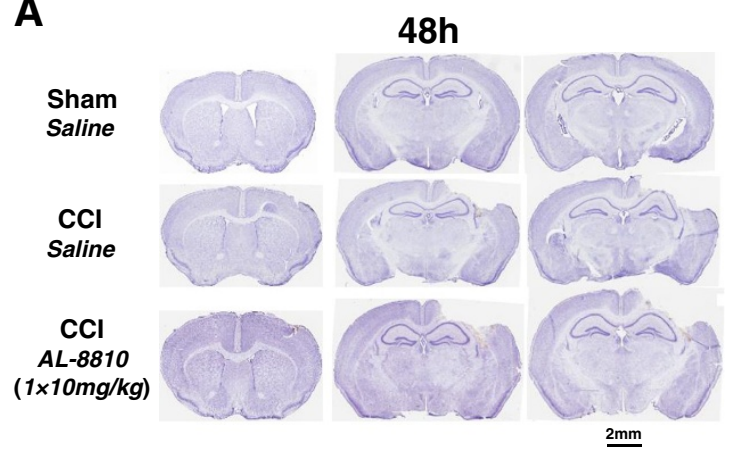

C

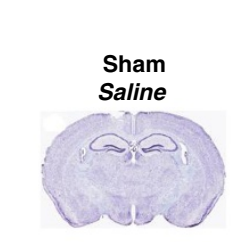

CCI

$A L-8810(1 \times 10 \mathrm{mg} / \mathrm{kg})$

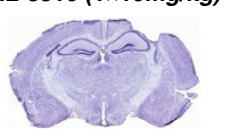

10d

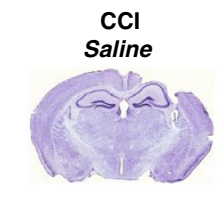

CCI

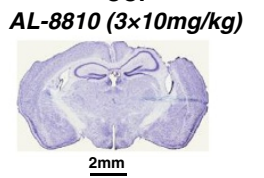

B

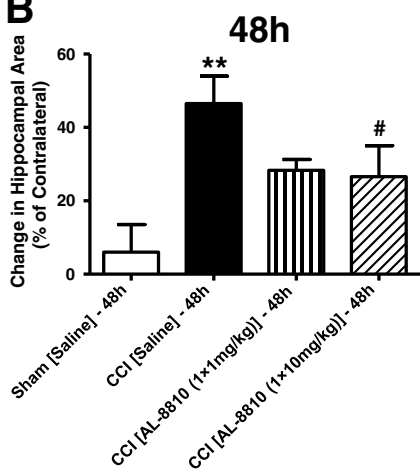

10d

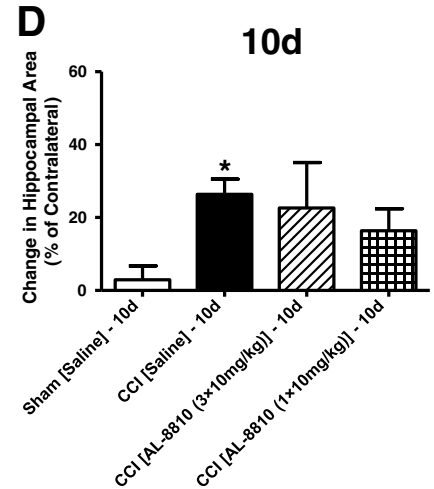

Figure 1 Brain pathology after controlled cortical impact (CCI): the effect of FP receptor blockade. (A) Representative photographs of cresyl violet-stained brain sections from sham and CCl-injured WT mice demonstrating cortical injury and hippocampal swelling in the areas between bregma one and two 48 hours after injury. (B) Quantitative analysis of the hippocampal area demonstrating a significant increase in relative hippocampal areas normalized to contralateral side in the ipsilateral hemisphere and significant decrease of hippocampal swelling in AL-8810- (10 mg/kg) treated mice 48 hours after CCI. (C) Representative photographs of cresyl-violet stained brain sections from sham and CCI-injured WT mice demonstrating cortical cavitation and remaining hippocampal swelling in the areas ten days after injury. (D) Quantitative analysis of relative hippocampal areas normalized to the contralateral side in saline- and AL-8810- $(10 \mathrm{mg} / \mathrm{kg})$ treated WT mice that underwent $\mathrm{CCl}$ or sham. The data demonstrate a significant hippocampal swelling ten days after injury compared with sham group, whereas there are no significant differences between relative hippocampal area values between two treatment groups that underwent $\mathrm{CCl}$, between sham and either of these treatment groups, or between CCl groups with saline and drug treatments. Data are presented as mean \pm SEM, ${ }^{*} P<0.05,{ }^{* *} P<0.01$, versus saline-treated sham group, and ${ }^{\#} P<0.05$, versus saline-treated $\mathrm{CCl}$ group, one-way ANOVA followed by Tukey's multiple comparison test $(n=7$ to 9$)$.

between saline and treatment groups of mice who underwent CCI.

\section{Effect of selective FP antagonist AL-8810 on the neurobehavioral outcomes}

Neurobehavioral assessment was performed at 24 and 48 hours after CCI or sham. CCI caused marked neurological impairment in saline-treated CCI mice as reflected in increased NDS, whereas no or only marginal neurological symptoms were observed in the sham animals. Figure 1A demonstrates a significant neurological impairment following $\mathrm{CCI}$ at the 24- and 48-hour time points compared with sham animals. The NDS in CCI animals was not significantly different between the two tested time points. Our data indicate that a single post-treatment with AL-8810 at a dose of $10 \mathrm{mg} / \mathrm{kg}$ significantly improved the NDS at both tested time points 24 and 48 hours after CCI, whereas the effect of a single $1 \mathrm{mg} / \mathrm{kg}$ dose was not significant (Figure 2A). To determine if repeated treatment with AL-8810 would have additional benefits compared with a single treatment, a separate group of mice that had NDS assessed at 24 hours and that had received one treatment immediately after CCI were given an additional treatment 24 hours after CCI and the first NDS assessment according to the repeated treatment protocol used in this study, and the NDS in these mice was assessed second time at 48 hours after CCI (Figure 2B). The data demonstrated that following a second AL-8810 treatment, NDS values were not further improved compared with a single treatment.

The grip test was used as an additional test to assess neuromuscular function following CCI by measuring maximal muscle strength of forelimbs as a primary phenotype screen. To measure forelimb strength, three 


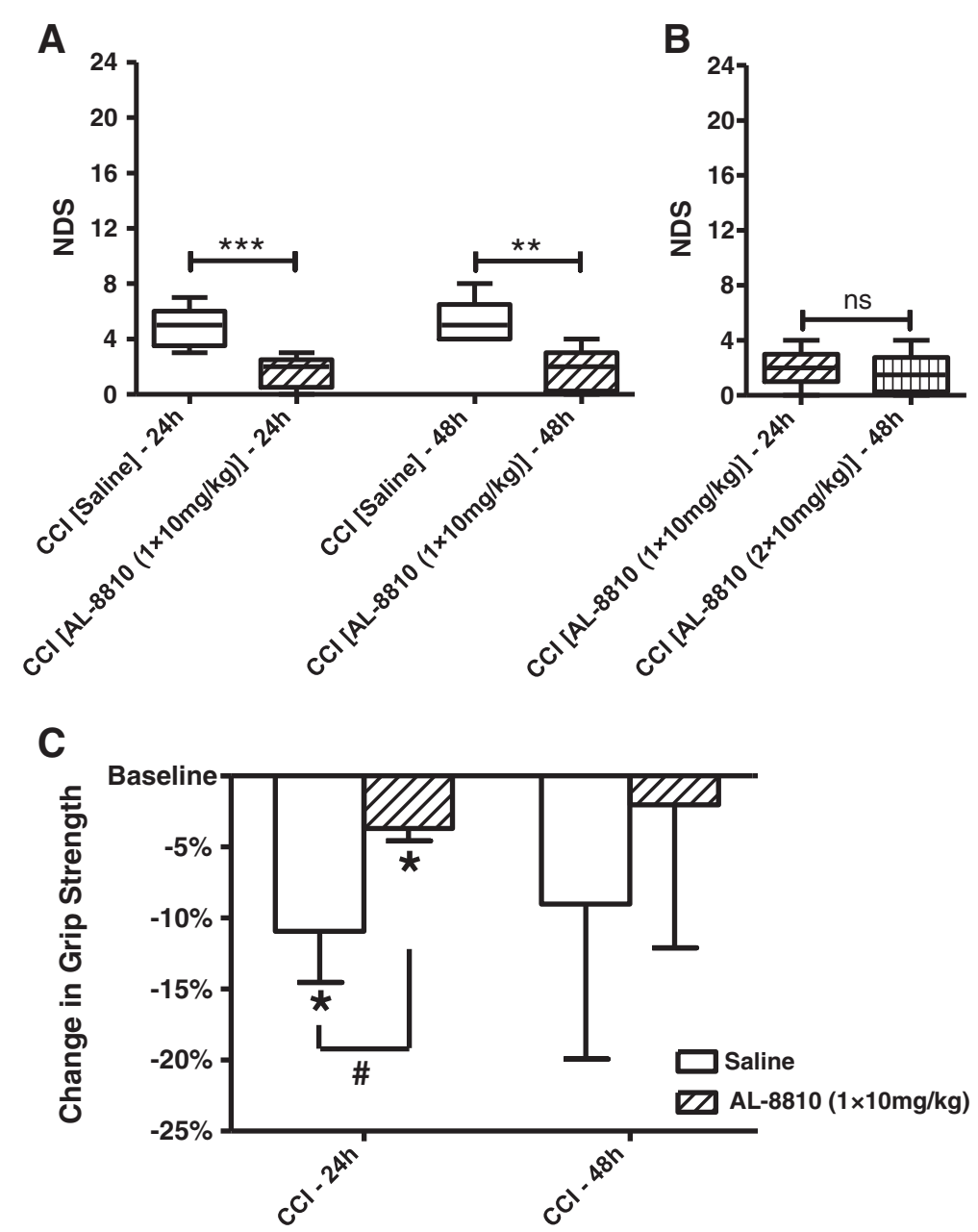

Figure 2 FP receptor blockade improves behavioral outcomes after controlled cortical impact (CCI). (A) Neurological deficit scores (NDS) in CCl-injured WT mice 24 and 48 hours after injury. Post-treatment AL-8810 (10 mg/kg) significantly improved NDS at both time points, ${ }^{* *} P<0.01,{ }^{* *} P<0.001$, Kruskal-Wallis ANOVA on ranks followed by Dunn's multiple comparison test $(n=5$ to 9$)$. (B) Comparison of NDS between a single dose of AL-8810 (10 mg/kg) 24 hours after injury and two doses of AL-8810 (10 mg/kg, once a day) 24 and 48 hours after injury in the same mice that underwent CCl. The data were obtained in a separate cohort of mice. 'ns' denotes not statistically different, Wilcoxon matched-pairs signed rank test $(P=0.6, n=8)$. (C) Changes in grip strength in CCl-injured WT mice 24 and 48 hours after injury. Post-treatment AL-8810 $(10 \mathrm{mg} / \mathrm{kg})$ significantly improved CCl-induced impairment in grip strength at 24 hours. ${ }^{*} P<0.05$, paired Student's $t$-test versus baseline. $\# P<0.05$, one-way ANOVA followed by Tukey's multiple comparison test, $\mathrm{n}=3$ in each group.

sets containing three consecutive trials each were carried out before the CCI procedure and 24 and 48 hours after $\mathrm{CCI}$ (Figure 2C). The mice were randomly divided in two groups: control and experimental. The average baseline values were $186.11 \pm 3.89 \mathrm{~g}$ and $193.67 \pm 10.65 \mathrm{~g}$ in control and experimental groups, respectively, and these values were not significantly different (data presented as mean \pm standard deviation, $P=0.3$, independent Student's $t$-test, $\mathrm{n}=3$ in each group). Both groups were subjected to $\mathrm{CCI}$, and the experimental group received single intraperitoneal injections of AL-8810 at a dose of $10 \mathrm{mg} / \mathrm{kg}$, whereas the control group received single injections of saline. CCI caused a significant decrease in the grip strength 24 hours post-CCI in the saline-treated group, but to a significantly lesser extent in the AL-8810- treated group compared with the corresponding baseline values in these groups. This experiment showed that in the AL-8810-treated animals 24 hours after CCI, the decrease in the grip strength was significantly improved to about $50 \%$ of the value observed in saline-treated animals, although at 48 hours, the changes in grip strength values were no longer significantly different.

\section{Effect of FP receptor knockout anatomical and neurobehavioral outcomes following $\mathrm{CCl}$}

Based on our published data demonstrating the neuroprotective effect of genetic FP receptor deletion in ischemic stroke models [21,22], we have tested this hypothesis to see if similar improvement could be achieved in the TBI model. Cortical lesion size and hippocampal swelling in 
$\mathrm{FP}^{-1-}$ mice were assessed 48 hours following CCI using cresyl violet staining on $30-\mu \mathrm{m}$ cryostat brain sections, and behavioral outcomes were assessed using NDS.

Based on the data that strain-dependent variability in cerebral vascular anatomy might be associated with different susceptibility to cerebral ischemia [30], and knowing the importance of vascular damage in TBI, we looked at anatomical differences between WT and $\mathrm{FP}^{-/-}$ mice in the major cortical arteries that might potentially affect outcome in the CCI model. Detailed morphological analysis of ACA and MCA using black latex paint showed that there were no significant differences in total numbers of anastomoses and the location of the line of anastomosis between the two groups (Figure 3).

Hippocampal swelling in $\mathrm{FP}^{-/-}$mice that underwent CCI were not significantly different from sham $\mathrm{FP}^{-/-}$animals. However, hippocampal swelling was significantly lower compared with saline-treated WT mice from the CCI group. Post-treatment with $10 \mathrm{mg} / \mathrm{kg}$ AL-8810 also had no additional effect. In addition, a group of $\mathrm{FP}^{-/-}$mice were post-treated with AL-8010 to test the specificity of the protective effect of this drug candidate (Figure 4, A and B). No significant differences in anatomical outcomes between AL-8010 and saline treatments were observed in the $\mathrm{FP}^{-/-}$mice.

Also, when using severe CCI parameters, NDS 24 and 48 hours after injury was not significantly different between saline-treated $\mathrm{WT}$ and $\mathrm{FP}^{-/-}$mice (Figure $4 \mathrm{C}$ ). In the $\mathrm{FP}^{-/-}$mice, post-treatment with $\mathrm{AL}-8810$ at the highest dose of $10 \mathrm{mg} / \mathrm{kg}$ also had no significant effect on the NDS.

\section{Effect of selective FP antagonist AL-8810 on the microglial activation and astrogliosis following $\mathrm{CCl}$}

Knowing the important role of microglia and astrocytes in TBI [31], to investigate putative protective mechanisms of AL-8810 in the brain, we performed immunohistochemical studies to detect changes in the brain levels of microglial and astrocytic markers in WT mice 48 hours and 10 days following injury. In addition, to study the role of the FP receptor in the brain following brain injury, and possible involvement of this receptor in microglial activation and astrogliosis, the changes in the brain levels of microglial and astrocytic markers were studied in the $\mathrm{FP}^{-/-}$mice 48 hours after CCI, similar to that of the WT mice. Forty-eight hours after injury, CCI caused apparent microglial activation detected as increased Iba1 immunoreactivity in the surrounding areas of cortical injury, referred to as a penumbra, as well as in the ipsilateral hippocampus and some thalamic regions within lateral dorsal and posterior nuclei compared to corresponding contralateral areas. In the CCI-injured animals, increased Iba1 immunoreactivity was accompanied by morphological changes in the immunopositive cells. Figure 5A shows
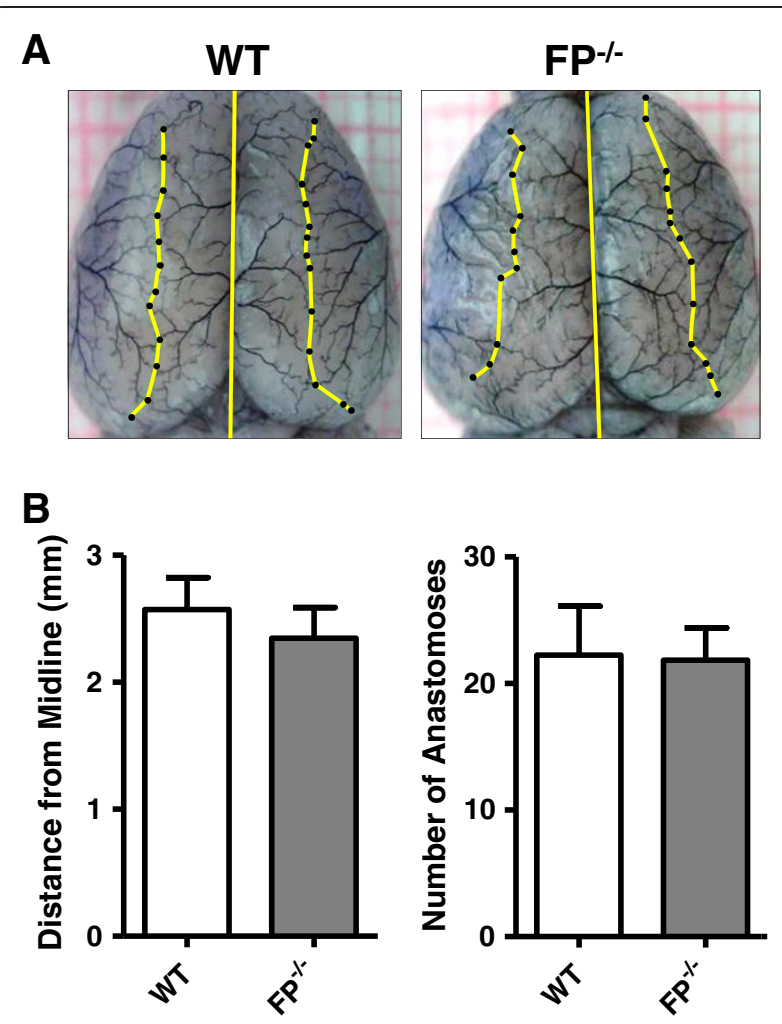

Figure 3 Distance from the midline and number of anastomoses in wildtype (WT) and FP receptor knockout (FP ${ }^{-/-}$) mice. (A) Representative photographs of cortical surface of brains from $\mathrm{WT}$ and $\mathrm{FP}^{-/-}$mice perfused with black latex paint. Yellow lines and black dots illustrate lines and points of anastomosis. Bar graphs represent mean values of total number of anastomoses for both hemispheres (B) and mean distances from midline (C) in WT $(n=9)$ and $\mathrm{FP}^{-/-}(\mathrm{n}=6)$ mice. Data presented as mean \pm standard deviation. No significant differences were observed between the values in WT and $\mathrm{FP}^{-1-}$ mice when using unpaired Student's t-test.

microphotographs that represent typical morphological changes in the Iba1-positive cells in the hippocampus, suggesting activation of microglia in the ipsilateral compared with contralateral area. A slight increase was shown in Iba1 levels in the ipsilateral cortical area surrounding craniotomy, but not in other brain regions, and was also observed in sham animals. However, the changes in the Iba1 levels in sham animals were substantially lower than in the cortical penumbra of the animals from the CCI group. In the AL-8810-treated animals, the morphological changes in the microglia were less strongly pronounced than in the saline-treated group. However, no statistical differences between relative immunoreactivities, normalized to the corresponding areas in the contralateral side, were detected between these two groups at 48 hours (Figure 5C). No apparent changes in the Iba1 immunoreactivity were observed between contralateral sides of sham- and CCItreated $\mathrm{FP}^{-/-}$mice (Figure 5B). Ten days after injury, Iba1 immunoreactivity was significantly increased in the cortical 


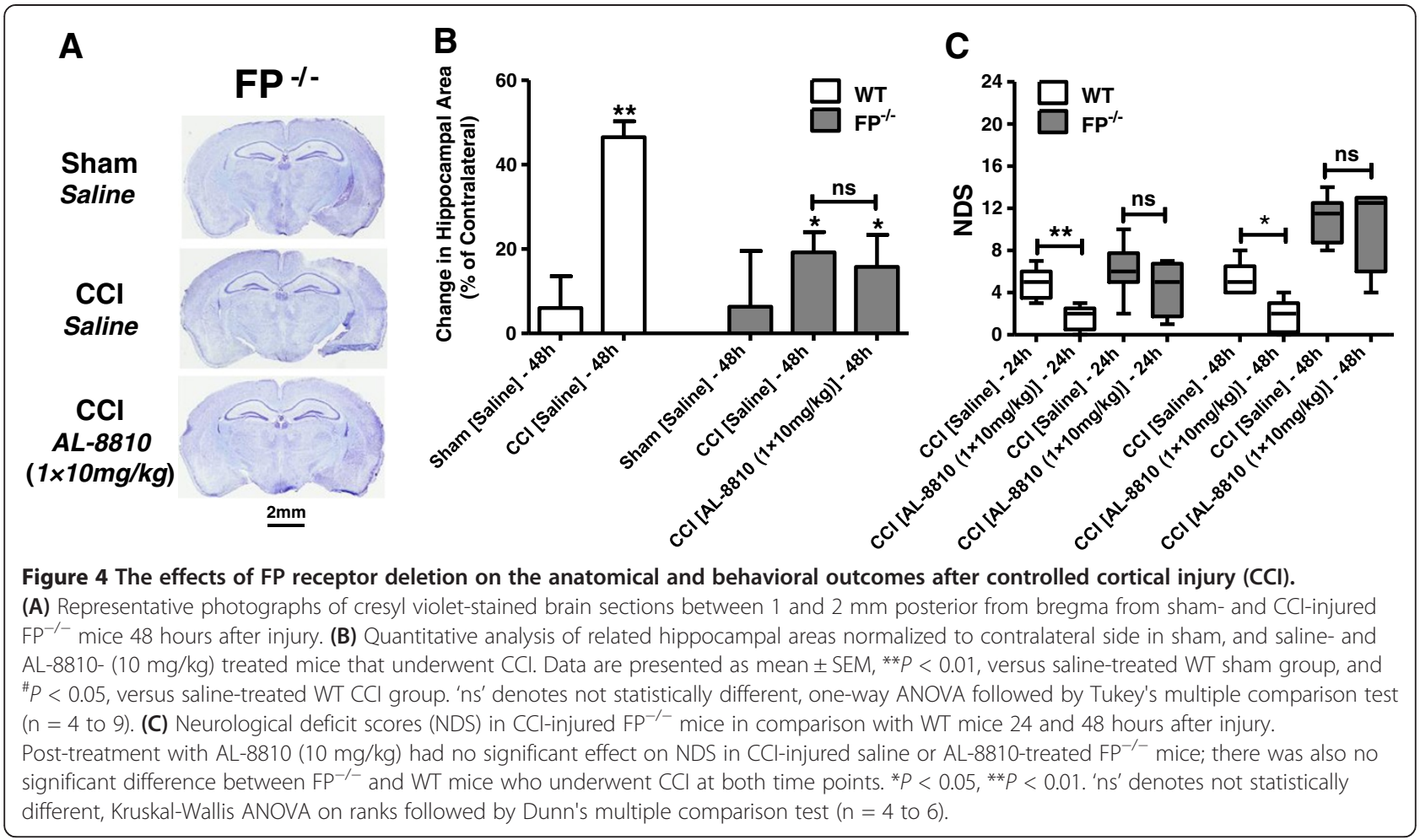

penumbra in the saline-treated CCI animals but not in AL-8810 treated-animals, whereas in the hippocampus, Iba1 immunoreactivity was decreased to the control level at this time point. The most significant improvement with single and repeated AL-8810 treatment was observed in the susceptible thalamic regions (Figure $5 \mathrm{C}$ ).

To study reactive gliosis, we used GFAP immunoreactivity. Similar to a microglial marker, the GFAP levels were considerably increased in the cortical penumbra, as well as in the ipsilateral hippocampus and thalamic areas compared with the corresponding contralateral areas in the CCI-treated animals at both time points used in the study. A small increase in the GFAP was observed in the cortical area surrounding craniotomy in the sham WT animals, and similar increases were observed in the sham- and CCI-treated $\mathrm{FP}^{-/-}$mice (Figure 6A). No detectable differences in the GFAP immunoreactivities between ipsilateral and contralateral hippocampus and thalamic regions were observed in sham-operated WT animals or in either shamor $\mathrm{CCI}$-injured $\mathrm{FP}^{-/-}$mice. In the cortical penumbra and hippocampus, the increase in the related GFAP immunoreactivities was observed at 48 hours, but not 10 days, after injury, whereas in the thalamus, the increased immunoreactivity remained up to 10 days. The changes in GFAP levels in the $\mathrm{FP}^{-/-}$mice were substantially lower compared with the CCI-treated WT animals (Figure 6B). In $\mathrm{FP}^{-/-}$ mice, no significant changes in GFAP immunoreactivity were detected in AL-8810 treatment groups compared with the saline group following CCI (Figure 6C).

\section{Discussion}

This study provides, for the first time, clarification of the respective role of the calcium-modulating FP receptor as a potential target for disease-modifying CNS drugs in the treatment of acute brain injury. Our data demonstrated significant anatomical and neurological improvements following pharmacological blockade of the FP receptor with a small-molecule-selective antagonist in a preclinical CCI mouse model, suggesting the involvement of this receptor in neuropathological consequences of acute brain trauma. In WT mice, post-treatment with AL-8810 following CCI significantly improved NDS and ameliorated grip strength impairment following CCI, and decreased CCI-induced hippocampal swelling and the level of markers of gliosis and microglial activation (that is, GFAP and Iba1) in susceptible brain regions 48 hours and 10 days following experimental brain injury. Furthermore, morphological analyses of cerebral vasculature and anastomoses in WT and $\mathrm{FP}^{-1-}$ mice confirmed that there are no differences between these strains. In the $\mathrm{FP}^{-/-}$mice, the hippocampal swelling and accumulation of astrocytic and microglial markers in the brain were substantially lower than in WT mice, and post-treatment with AL-8810 had no additional benefits in $\mathrm{FP}^{-/-}$mice, indicating the selectivity of pharmacological action of this drug candidate on the FP receptor. Importantly, the beneficial effects of FP antagonist were achieved with a single systemic treatment, suggesting translational potential for this compound in clinical use, 


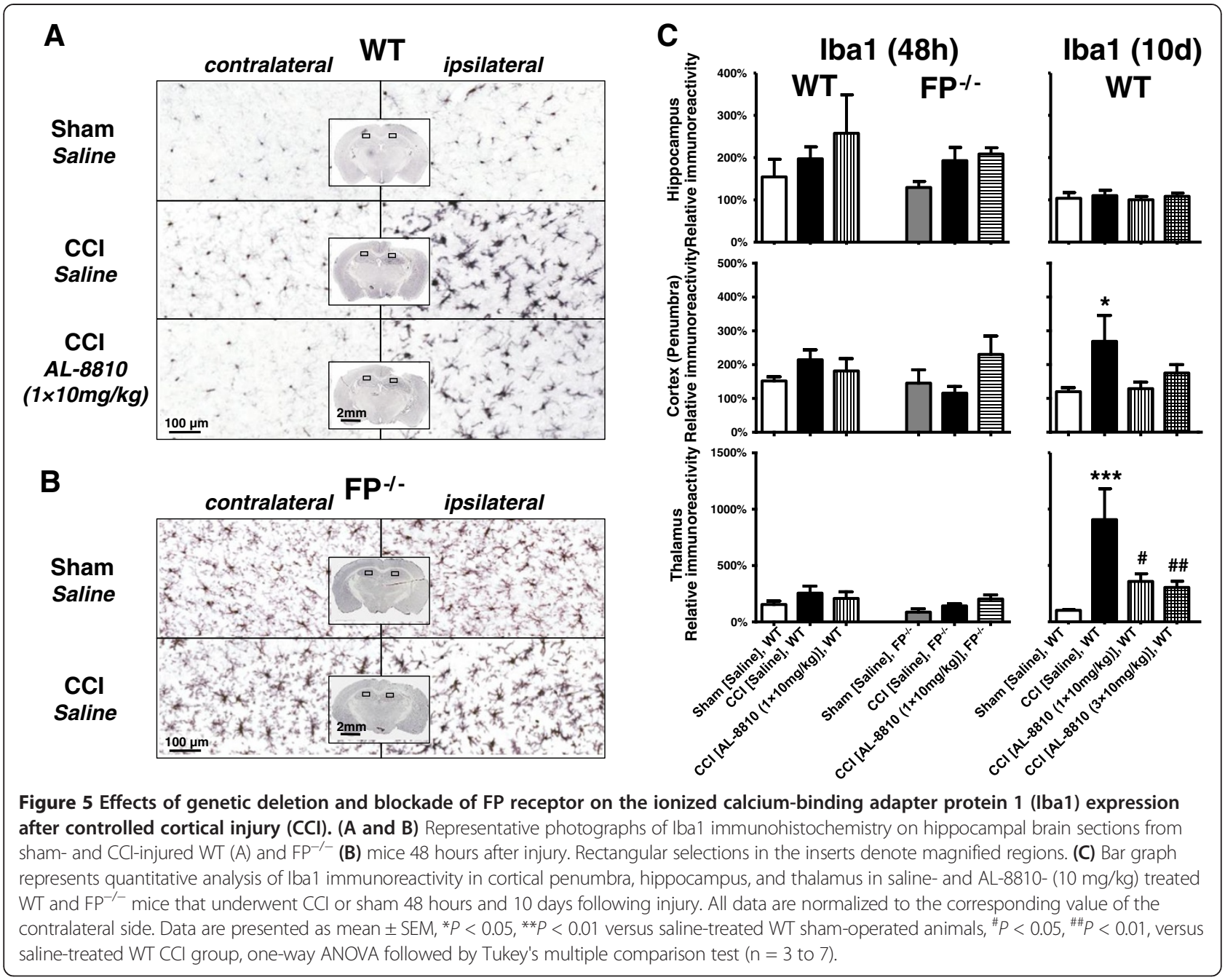

particularly in critical care settings for the management of TBI.

Our previous data suggested a potential therapeutic role for $\mathrm{PGF}_{2 \alpha}$ FP receptor blockade in preclinical ischemic stroke models [21,22]. Despite different epidemiology and etiologies of stroke and TBI, both conditions share many common pathophysiological features, including formation of ischemic penumbra and brain edema [32]. TBI is a complex disorder that causes brain damage through several coexisting mechanisms, including primary and secondary excitotoxicity, ischemia, brain hemorrhage, and after toxicity that has been caused by hemoglobin breakdown products, diffuse edema, and upregulation of proinflammatory mediators [33]. Vascular damage plays an important role in TBI and is a primary cause of hemorrhage in different brain regions to the extent correlated with TBI severity [34], extensive glutamate release [35], and cortical necrosis [34]. The hemorrhagic component itself could trigger secondary biochemical cascades, exacerbating primary brain damage involving oxygen free radicals, membrane lipid peroxidation, glutamate receptor upregulation, and excitotoxicity [36,37]. Neuroinflammatory pathways involving COX-2 upregulation have been considered to be involved with pathological sequelae of TBI $[12,13]$. Experimental reports and clinical data suggest that COX-2 upregulation and subsequent increases in the levels of several classes of prostaglandins, notably $\mathrm{PGF}_{2 \alpha}$, are involved in numerous neurological disorders. In mammalians, expression of the FP receptor has been demonstrated in whole brain homogenates [38], brain synaptosomes [39], and cerebral microvessels [40]. In addition, it has been reported that the FP receptor is expressed in cultured cortical neurons [41] and astrocytes [42].

The role of the FP receptor in the brain is not well understood. It has been shown that this receptor is involved differently in the pathological pathways in animal models of stroke [21,22] and seizures [43]. In addition, $\mathrm{PGF}_{2 \alpha}$ induces cerebral vasoconstriction in adults and newborns, though in the latter case to a substantially lesser extent $[44,45]$. A significant increase in $\mathrm{PGF}_{2 \alpha}$ was 


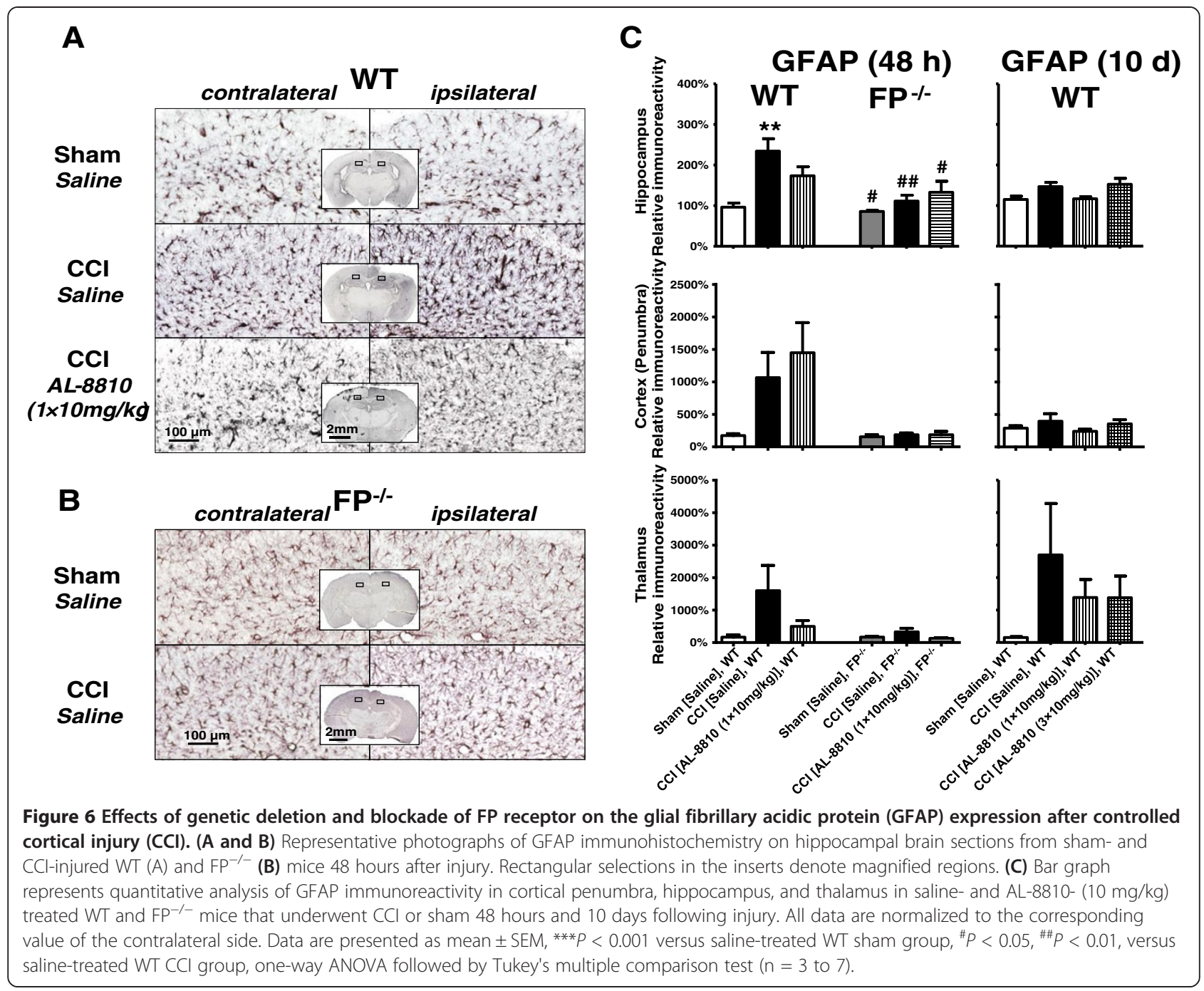

demonstrated in the cerebrospinal fluid (CSF) of patients with stroke and subarachnoid hemorrhage when samples were collected shortly after the cerebral attack, which then decreased with the regression of clinical symptoms $[46,47]$. However, other studies found no relationship between $\mathrm{PGF}_{2 \alpha}$ level in lumbar CSF and neurological deficit [48]. Experimental study further suggests that the $\mathrm{PGF}_{2 \alpha}$ concentration in lumbar CSF might not reflect its intracranial level depending on the size and location of the hemorrhage [47]. Clinical data indicate the COX-2 upregulation in hippocampal biopsies from patients with therapy-refractive temporal lobe epilepsy [49], which is consistent with the previous findings of increased concentrations of $\mathrm{PGF}_{2 \alpha}$ in the CSF of epilepsy patients $[46,50]$. Increased CSF PGF ${ }_{2 \alpha}$ levels have also been observed in infants and children with febrile convulsions [51], which have been recently proposed as a risk factor for development of temporal lobe epilepsy [52,53]. Other evidence supporting the proconvulsive properties of
$\mathrm{PGF}_{2 \alpha}$ include several cases of seizures and abnormal electroencephalographic changes associated with the clinical use of $\mathrm{PGF}_{2 \alpha}$ analogs to terminate pregnancy that have been reported in clinical practice [54-57]. Nevertheless, action $\mathrm{PGF}_{2 \alpha}$ is disputed and the FP receptor role still remains controversial [58]. Several contrary experimental reports demonstrated that administration of $\mathrm{PGF}_{2 \alpha}$ caused seizure aggravation [59] and abolished the anticonvulsant effects of other prostaglandins [60,61], whereas others suggested that elevated levels of $\mathrm{PGF}_{2 \alpha}$ might have anticonvulsant action [43,62]. The level of arachidonic acid, a precursor of prostaglandin synthesis, significantly increases in the cortex and hippocampus after $\mathrm{CCI}$ in rodents, and it has been suggested that arachidonic acid metabolites, including $\mathrm{PGF}_{2 \alpha}$, may play a role as mediators in the blood-brain barrier breakdown [63,64], which might be associated with edema formation in TBI [65]. On the molecular level, activation of the FP receptor initiates several events, including stimulation of the 
phospholipase $\mathrm{C} / \mathrm{IP}_{3} \mathrm{R} / \mathrm{Ca}^{2+}$ signaling pathway $[6,21]$. By this means, supraphysiological levels of $\mathrm{PGF}_{2 \alpha}$ may potentially lead to intracellular calcium overload [21], which could consequently lead to excessive release of excitatory neurotransmitters, or could even trigger neuronal necrosis via activation of calpains [66].

In this study, we used male WT and $\mathrm{FP}^{-/-}$mice of the same C57BL/6 background. Strain-dependent differences in the response to the experimental brain trauma have been reported in rats $[67,68]$ and mice $[69,70]$. Some studies in mouse stroke models have demonstrated that strain-dependent differences in cerebrovascular anatomy are associated with susceptibility to cerebral ischemia [30], although others suggest an involvement of intrinsic genetic determinants in ischemia and glutamate excitotoxicity-induced cell death $[28,71]$. Our previous data, obtained in an ischemia model, indicated that genetic deletion of the FP receptor does not affect the vital physiological parameters in mice. No substantial differences in cerebral blood flow, body temperature, mean arterial blood pressure, blood gases $\left(\mathrm{PaO}_{2}\right.$, $\mathrm{PaCO}_{2}$ ), or $\mathrm{pH}$ between WT and $\mathrm{FP}^{-/-}$mice were observed before, during stroke, or after reperfusion [22]. This study also demonstrated no significant differences in anastomoses of two major cerebral arteries. Taken together, these data suggest that differences between anatomical and neurological outcomes between WT and $\mathrm{FP}^{-/-}$mice are associated with the FP receptor deletion.

In this study, AL-8810 significantly improved anatomical and neurological outcomes in a preclinical TBI model. It is well known that regional vulnerability of the brain is characteristic for TBI. In unilateral TBI models performed in adult animals, neuronal damage is mostly located in the cortex and hippocampus of the ipsilateral hemisphere, whereas in immature animals, significant neuronal loss is more widespread and includes ipsilateral hippocampus and ipsilateral thalamus, as well as the ipsilateral and the contralateral cortices compared to sham [72]. A noticeable hippocampal swelling was also observed 48 hours and 10 days after CCI in saline-treated animals. The decrease in the CCI-induced hippocampal swelling in animals post-treated with AL- 8810 suggests involvement of the FP receptor in edema formation following brain trauma. One of the possible mechanisms is that overactivation of the FP receptor promotes the blood-brain barrier breakdown and aggravates edema formation [63,64]. Brain edema starts within minutes after TBI, and becomes progressively more severe over time, peaks at 24 hours after injury, and begins to decline after the third day $[73,74]$. Based on the increase in water content and Evans blue dye extravasation in the injured ipsilateral cortex and hippocampus, it has been suggested that the blood-brain barrier opening after CCI is biphasic [75]. The first blood-brain barrier breakdown occurs within four and six hours, and the second opening occurs on the third day after injury in the ipsilateral cortex and hippocampus [73]. However, the second opening of the blood-brain barrier does not contribute to a further increase in edema formation [73]. Our data indicating that repeated AL-8810 treatment provides no additional benefits compared with a single AL-8810 post-treatment is consistent with the putative role of only the first blood-brain barrier breakdown in edema development. Furthermore, these data suggest that the blockade of the FP receptor with a smallmolecule antagonist at early time points might be an effective treatment for brain edema in TBI.

In addition, significant improvement in NDS and grip strengths were observed in the AL-8810-treated group compared with saline-treated animals. The improvements in NDS were dependent on AL-8810 dosage. The treatment was effective when the drug was administered following CCI at single dose, and additional AL-8810 injection did not cause significant improvement in NDS compared with single dosage. The grip strength test is included in the functional observational battery for use in the neurotoxicity studies in rodents to access neuromotor function [76]. In addition, clinical data indicate that grasping is impaired in children after TBI [77], and the quantitative analysis of precision-grip forces has been proposed as a sensitive method to assess recovery of fine motor skills [77,78]. Our data indicate a significant decrease in grip strength following $\mathrm{CCI}$, and the decrease in grip strength was three-fold less in the AL-8810-treated group, which suggests that the FP receptor blockade might protect neuromotor function or facilitate its recovery following CCI.

Another important finding of this study is that anatomical brain injury is significantly reduced in $\mathrm{FP}^{-/-}$ mice. Interestingly, the anatomical improvement was not associated with the acute neurological outcome observed in AL-8810-treated WT mice. This finding suggests a dual role for the FP receptor in TBI recovery, and that activation of this receptor, at some level, might be beneficial for short-term outcomes. On the other hand, the beneficial effect of AL-8810 in WT mice could be explained by the unique pharmacological properties of this compound. In the studies performed in different cell lines, AL-8810, in addition to its antagonist properties, has been shown to be a partial agonist with approximately 20\% efficacy at the endogenous FP receptor [23].

Although the FP receptors play important roles in different systems of mammalian organism overall, with a few exceptions, the effects of the FP receptor activation are believed to be pathophysiological; thus, more close attention may be paid to development of FP receptor antagonists as promising agents for treatment of diverse acute and chronic conditions, including preterm labor, 
cardiovascular disease, and fibroses (reviewed in [6]). Our data presented here indicate that a single treatment with AL-8810 applied immediately after CCI was sufficient to produce a beneficial effect on neurological outcome. Surprisingly, NDS outcomes after experimental TBI were not affected in $\mathrm{FP}^{-/-}$mice compared to WT mice, indicating that the FP receptor may play a role in some aspects of neural behavior. This finding is in contrast with published data from our group obtained in stroke models where genetic deletion of the FP receptor improved neurobehavioral outcomes in models of ischemic stroke and excitotoxicity [21,22]. On the other hand, the published data with the prostaglandin $E_{2}$ EP1 receptor, which has a similar structure and functions as the FP receptor $[6,7,79]$, suggest that the effects of pharmacological blockade or genetic deletion of the EP1 receptor might be opposite in ischemic and hemorrhagic stroke [8,80-82]. Thereby, lack effect of FP knockout in TBI might be explained by the complexity of its pathology, which also includes a hemorrhagic component. Our data also suggest that resolving of acute hippocampal edema and gliosis, assessed by GFAP immunohistochemistry, lead to functional recovery and reduction of delayed inflammation and microglia activation in susceptible brain regions assessed by Iba1 immunohistochemistry. Thus, therapeutic strategy with a single-dose treatment would be optimal to obtain beneficial effects and minimize possible side effects in clinical applications.

In this study, significant improvements in the levels of microglial activation and reactive gliosis, assessed immunohistochemically, were detected in the selected brain regions of $\mathrm{FP}^{-/-}$mice and WT mice that underwent treatment with AL-8810 following experimental TBI. In addition, in the $\mathrm{FP}^{-/-}$mice, AL-8810 did not cause detectable changes in the Iba1 and GFAP immunoreactivities compared with saline (Additional file 1: Figure S1, $B$ and C). Interestingly, similar beneficial effects of AL-8810 were observed with single and repeated treatment. Although further detailed studies are warranted to determine the exact therapeutic window of administration for the FP receptor antagonist in treatment of $\mathrm{TBI}$, the data in the literature indicate that the upregulation of the inducible COX-2 enzyme occurs within several hours [12,14-16] and that the increased levels of the prostaglandin precursor remained for several days following brain trauma [18], suggesting a potential clinical application for prospective drugs in critical care. It is important to note that the role of COX-2 in brain injury is complex $[15,16]$ and that the FP receptor antagonist selectively targets a downstream proinflammatory cascade of cyclooxygenase, leaving intact potentially neuroprotective ones. For example, we and others have previously shown that pathways involving prostaglandin $\mathrm{PGE}_{2}$ receptors EP2 and EP4 were demonstrated in preclinical excitotoxic and ischemic animal models $[81,83,84]$.

\section{Conclusions}

This study suggests that the $\mathrm{PGF}_{2 \alpha} \mathrm{FP}$ receptor is involved in neuroinflammatory pathways and contributes to the overall pathology of brain trauma, and taking into account the similarity of prostaglandin drugs used in the clinic, selective FP antagonists could be used therapeutically in acute brain insult. Our findings provide a novel target for the treatment of TBI and help to elucidate the therapeutic potential and role of the FP receptor in acute brain trauma that will lead to more efficient and safe therapies; thus improving the quality of life of TBI patients for which effective treatment is currently unavailable.

\section{Additional file}

Additional file 1: Figure S1. Lack of effects of AL-8810 post-treatment on brain pathology, gliosis, and microglia activation after sham surgery. (A) Representative photographs of bran sections from sham-injured WT mice post treated with a single dose of AL-8810 (10 mg/kg) 10 days after surgery stained with cresyl violet (A), and DAB immunostained for GFAP (B) and Iba1 (C). Top panels: examples of four brain sections cut throughout the entire craniotomy area. Middle panels: photographs of the stained and immunostained brain sections cut between 1 and $2 \mathrm{~mm}$ posterior from bregma zoomed in to demonstrate ipsilateral and contralateral susceptible brain regions (that is, cortical penumbra, hippocampus, and lateral dorsal and posterior nuclei of the thalamus). Bottom panels: zoomed area photographs presented in middle panels to demonstrate CA1 region of hippocampus, corpus callosum, and cortex in thinner details. Similar to saline-treated sham animals, no differences were observed between ipsilateral and contralateral sides in sham mice post-treated with AL-8810. The presented data is representative for a group of four mice.

\section{Abbreviations \\ ACA: Anterior cerebral artery; CCl: Controlled cortical impact; COX-2: Cyclooxygenase-2; CSF: Cerebrospinal fluid; FP ${ }^{-/-}$: FP receptor knockout; GFAP: Glial fibrillary acidic protein; Iba1: Ionized calcium-binding adapter protein 1; MCA: Middle cerebral artery; NDS: Neurological deficit scores; $\mathrm{PaCO}_{2}$ : Partial pressure of carbon dioxide in arterial blood; $\mathrm{PaO}_{2}$ : Partial pressure of oxygen in arterial blood; PBS: Phosphate-buffered saline; WT: Wildtype.}

\section{Competing interests}

The authors have no competing interests to declare.

\section{Authors' contributions}

AVG contributed to the study design, in vivo experiments, immunohistochemistry, data analysis, interpretation of results and writing of the manuscript; SWR contributed to the experiments and analysis of cerebrovascular morphology; CLB contributed to the immunohistochemistry, data analysis, and reviewing of the manuscript; SN contributed to the development of $\mathrm{FP}^{-/-}$mouse; SD contributed to the study design, interpretation of results, and writing and revision of the manuscript. All authors have read and approved the manuscript for publication.

\section{Acknowledgements}

This work was supported by a grant from the McKnight Brain Research Foundation, Brain and Spinal Cord Injury Research Trust Fund, and the National Institute of Heath NS046400. Special thanks to Mr. Gerald R Boley, Jr. for technical assistance with immunohistochemistry, and to all Doré lab members for all their generous assistance. 


\section{Author details}

'Department of Anesthesiology, University of Florida College of Medicine, PO Box 100159, Gainesville, FL 32610, USA. ²Department of Pharmacology, Kyoto University Faculty of Medicine, Yoshida, Sakyo-ku, Kyoto 606, Japan. ${ }^{3}$ Departments of Neuroscience, Neurology, Psychiatry, and Center for Translational Research in Neurodegenerative Disease, University of Florida College of Medicine, 1275 Center Drive, Biomed Sci J493, PO Box 100159, Gainesville, FL 32610, USA.

Received: 18 June 2013 Accepted: 4 October 2013

Published: 30 October 2013

\section{References}

1. Saatman KE, Duhaime AC, Bullock R, Maas Al, Valadka A, Manley GT: Classification of traumatic brain injury for targeted therapies. J Neurotrauma 2008, 25:719-738.

2. Mclntosh TK, Smith DH, Meaney DF, Kotapka MJ, Gennarelli TA, Graham Dl: Neuropathological sequelae of traumatic brain injury: relationship to neurochemical and biomechanical mechanisms. Lab Invest 1996, 74:315-342.

3. Loane DJ, Faden Al: Neuroprotection for traumatic brain injury: translational challenges and emerging therapeutic strategies. Trends Pharmacol Sci 2010, 31:596-604.

4. Kochanek PM, Bramlett H, Dietrich WD, Dixon CE, Hayes RL, Povlishock J, Tortella FC, Wang KK: A novel multicenter preclinical drug screening and biomarker consortium for experimental traumatic brain injury: operation brain trauma therapy. J Trauma 2011, 71:S15-S24.

5. Bazan NG, de Turco EB R, Allan G: Mediators of injury in neurotrauma: intracellular signal transduction and gene expression. J Neurotrauma 1995, 12:814.

6. Woodward DF, Jones RL, Narumiya S: International union of basic and clinical pharmacology. LXXXIII: classification of prostanoid receptors, updating 15 years of progress. Pharmacol Rev 2011, 63:471-538.

7. Mohan S, Ahmad AS, Glushakov AV, Chambers C, Doré S: Putative role of prostaglandin receptor in intracerebral hemorrhage. Front Neurol 2012, 3:145.

8. Doré S: GPCR antagonists as an alternative to COX-2 inhibitors: a case for the PGE 2 EP1 receptor. Trends Pharmacol Sci 2006, 27:458-460.

9. Toti P, DEF C, Schurfeld K, Stumpo M, Bartolommei S, Lombardi A, Petraglia E, Buonocore G: Cyclooxygenase-2 immunoreactivity in the ischemic neonatal human brain. An autopsy study. J Submicrosc Cytol Pathol 2001, 33:245-249.

10. Tomimoto H, Akiguchi I, Wakita H, Lin JX, Budka H: Cyclooxygenase-2 is induced in microglia during chronic cerebral ischemia in humans. Acta Neuropathol (Berl) 2000, 99:26-30.

11. Tomimoto H, Shibata M, Ihara M, Akiguchi I, Ohtani R, Budka H: A comparative study on the expression of cyclooxygenase and 5-lipoxygenase during cerebral ischemia in humans. Acta Neuropathol (Berl) 2002, 104:601-607.

12. Cernak I, O'Connor C, Vink R: Activation of cyclo-oxygenase-2 contributes to motor and cognitive dysfunction following diffuse traumatic brain injury in rats. Clin Exp Pharmacol Physiol 2001, 28:922-925.

13. Kunz T, Marklund N, Hillered L, Oliw EH: Cyclooxygenase-2, prostaglandin synthases, and prostaglandin $\mathrm{H} 2$ metabolism in traumatic brain injury in the rat. J Neurotrauma 2002, 19:1051-1064.

14. Cernak I, O'Connor C, Vink R: Inhibition of cyclooxygenase 2 by nimesulide improves cognitive outcome more than motor outcome following diffuse traumatic brain injury in rats. Exp Brain Res 2002, 147:193-199.

15. Dash PK, Mach SA, Moore AN: Regional expression and role of cyclooxygenase- 2 following experimental traumatic brain injury. J Neurotrauma 2000, 17:69-81.

16. Strauss Kl, Barbe MF, Marshall RM, Raghupathi R, Mehta S, Narayan RK. Prolonged cyclooxygenase-2 induction in neurons and glia following traumatic brain injury in the rat. J Neurotrauma 2000, 17:695-711.

17. Homayoun P, Parkins NE, Soblosky J, Carey ME, Rodriguez De Turco EB, Bazan NG: Cortical impact injury in rats promotes a rapid and sustained increase in polyunsaturated free fatty acids and diacylglycerols. Neurochem Res 2000, 25:269-276.

18. Homayoun P, Rodriguez De Turco EB, Parkins NE, Lane DC, Soblosky J, Carey ME, Bazan NG: Delayed phospholipid degradation in rat brain after traumatic brain injury. J Neurochem 1997, 69:199-205.

19. Gopez JJ, Yue H, Vasudevan R, Malik AS, Fogelsanger LN, Lewis S, Panikashvili D, Shohami E, Jansen SA, Narayan RK, Strauss KI: Cyclooxygenase-2-specific inhibitor improves functional outcomes, provides neuroprotection, and reduces inflammation in a rat model of traumatic brain injury. Neurosurgery 2005, 56:590-604.

20. Topol EJ: Failing the public health - rofecoxib, Merck, and the FDA. N Engl J Med 2004, 351:1707-1709.

21. Kim YT, Moon SK, Maruyama T, Narumiya S, Doré S: Prostaglandin FP receptor inhibitor reduces ischemic brain damage and neurotoxicity. Neurobiol Dis 2012, 48:58-65.

22. Saleem S, Ahmad AS, Maruyama T, Narumiya S, Doré S: PGF(2alpha) FP receptor contributes to brain damage following transient focal brain ischemia. Neurotox Res 2009, 15:62-70.

23. Griffin BW, Klimko P, Crider JY, Sharif NA: AL-8810: a novel prostaglandin F2 alpha analog with selective antagonist effects at the prostaglandin F2 alpha (FP) receptor. J Pharmacol Exp Ther 1999, 290:1278-1284.

24. Yu S, Kaneko Y, Bae E, Stahl CE, Wang Y, van Loveren H, Sanberg PR, Borlongan CV: Severity of controlled cortical impact traumatic brain injury in rats and mice dictates degree of behavioral deficits. Brain Res 2009, 1287:157-163.

25. Clark W, Gunion-Rinker L, Lessov N, Hazel K: Citicoline treatment for experimental intracerebral hemorrhage in mice. Stroke 1998, 29:2136-2140.

26. Ahmad AS, Saleem S, Ahmad M, Doré S: Prostaglandin EP1 receptor contributes to excitotoxicity and focal ischemic brain damage. Toxicol Sci 2006, 89:265-270.

27. Maeda K, Hata R, Hossmann KA: Regional metabolic disturbances and cerebrovascular anatomy after permanent middle cerebral artery occlusion in C57black/6 and SV129 mice. Neurobiol Dis 1999, 6:101-108.

28. Majid A, He YY, Gidday JM, Kaplan SS, Gonzales ER, Park TS, Fenstermacher JD Wei L, Choi DW, Hsu CY: Differences in vulnerability to permanent focal cerebral ischemia among - 3 common mouse strains. Stroke 2000, 31:2707-2714.

29. Macleod MR, Fisher M, O'Collins V, Sena ES, Dirnagl U, Bath PM, Buchan A, van der Worp HB, Traystman R, Minematsu K, et al: Good laboratory practice: preventing introduction of bias at the bench. Stroke 2009, 40:e50-e52.

30. Barone FC, Knudsen DJ, Nelson AH, Feuerstein GZ, Willette RN: Mouse strain differences in susceptibility to cerebral ischemia are related to cerebral vascular anatomy. J Cereb Blood Flow Metab 1993, 13:683-692.

31. Loane DJ, Byrnes KR: Role of microglia in neurotrauma. Neurotherapeutics 2010, 7:366-377.

32. Bramlett HM, Dietrich WD: Pathophysiology of cerebral ischemia and brain trauma: similarities and differences. J Cereb Blood Flow Metab 2004, 24:133-150.

33. Diaz-Arrastia R, Agostini MA, Frol AB, Mickey B, Fleckenstein J, Bigio $E$, Van Ness PC: Neurophysiologic and neuroradiologic features of intractable epilepsy after traumatic brain injury in adults. Arch Neurol 2000, 57:1611-1616.

34. Sutton RL, Lescaudron L, Stein DG: Unilateral cortical contusion injury in the rat: vascular disruption and temporal development of cortical necrosis. J Neurotrauma 1993, 10:135-149

35. Matsushita Y, Shima K, Nawashiro H, Wada K, Tsuzuki N, Miyazawa T: Real time monitoring of glutamate following fluid percussion brain injury with hypoxia in the rat. Acta Neurochir Suppl 2000, 76:207-212.

36. Willmore $L$, Triggs WJ: Iron-induced lipid peroxidation and brain injury responses. Int J Dev Neurosci 1991, 9:175-180.

37. Doi T, Ueda Y, Tokumaru J, Mitsuyama Y, Willmore LJ: Sequential changes in AMPA and NMDA protein levels during Fe(3+)-induced epileptogenesis. Brain Res Mol Brain Res 2001, 92:107-114.

38. Muller K, Krieg P, Marks F, Furstenberger G: Expression of PGF $_{2 a}$ receptor mRNA in normal, hyperplastic and neoplastic skin. Carcinogenesis 2000, 21:1063-1066

39. Li DY, Varma DR, Chemtob S: Up-regulation of brain $\mathrm{PGE}_{2}$ and $\mathrm{PGF}_{2 a}$ receptors and receptor-coupled second messengers by cyclooxygenase inhibition in newborn pigs. J Pharmacol Exp Ther 1995, 272:15-19.

40. Li DY, Varma DR, Chemtob S: Ontogenic increase in PGE2 and PGF2 alpha receptor density in brain microvessels of pigs. Br J Pharmacol 1994, 112:59-64.

41. Carlson NG: Neuroprotection of cultured cortical neurons mediated by the cyclooxygenase- 2 inhibitor APHS can be reversed by a prostanoid. J Neurosci Res 2003, 71:79-88.

42. Kitanaka J, Onoe H, Baba A: Astrocytes possess prostaglandin F2 alpha receptors coupled to phospholipase C. Biochem Biophys Res Commun 1991, 178:946-952. 
43. Kim HJ, Chung Jl, Lee SH, Jung YS, Moon CH, Baik EJ: Involvement of endogenous prostaglandin F2alpha on kainic acid-induced seizure activity through FP receptor: the mechanism of proconvulsant effects of COX-2 inhibitors. Brain Res 2008, 1193:153-161.

44. Hadhazy P, Malomvolgyi B, Magyar K: Endogenous prostanoids and arterial contractility. Prostaglandins Leukot Essent Fatty Acids 1988, 32:175-185.

45. Hayashi S, Park MK, Kuehl TJ: Relaxant and contractile responses to prostaglandins in premature, newborn and adult baboon cerebral arteries. J Pharmacol Exp Ther 1985, 233:628-635.

46. Egg D, Herold M, Rumpl E, Gunther R: Prostaglandin F2 alpha levels in human cerebrospinal fluid in normal and pathological conditions. J Neurol 1980, 222:239-248

47. Hagen AA, Gerber JN, Sweeley CC, White RP, Robertson JT: Levels and disappearance of prostaglandin F2alpha in cerebral spinal fluid: a clinical and experimental study. Stroke 1977, 8:672-675.

48. Kostic VS, Djuricic BM, Mrsulja BB: Cerebrospinal fluid prostaglandin F2 alpha in stroke patients: no relationship to the degree of neurological deficit. Eur Neurol 1984, 23:291-295.

49. Desjardins P, Sauvageau A, Bouthillier A, Navarro D, Hazell AS, Rose C, Butterworth RF: Induction of astrocytic cyclooxygenase-2 in epileptic patients with hippocampal sclerosis. Neurochem Int 2003, 42:299-303.

50. Wolfe LS, Mamer OA: Measurement of prostaglandin F2alpha levels in human cerebrospinal fluid in normal and pathological conditions. Prostaglandins 1975, 9:183-192.

51. Tamai I, Takei T, Maekawa K, Ohta H: Prostaglandin F2 alpha concentrations in the cerebrospinal fluid of children with febrile convulsions, epilepsy and meningitis. Brain Dev 1983, 5:357-362.

52. Cendes F: Febrile seizures and mesial temporal sclerosis. Curr Opin Neurol 2004, 17:161-164.

53. Sharma AK, Reams RY, Jordan WH, Miller MA, Thacker HL, Snyder PW: Mesial temporal lobe epilepsy: pathogenesis, induced rodent models and lesions. Toxicol Pathol 2007, 35:984-999.

54. Wislicki L: Systemic adverse reactions to prostaglandin F2 (PGF2 alpha, dinoprostone, prostin F2 alpha, prostalmon F). Int J Biol Res Pregnancy 1982, 3:158-160.

55. Sederberg-Olsen J, Olsen CE: Prostaglandin-oxytocin induction of mid-trimester abortion complicated by grand mal-like seizures. Acta Obstet Gynecol Scand 1983, 62:79-81.

56. Lyneham RC, Low PA, McLeod JC, Shearman RP, Smith ID, Korda AR: Convulsions and electroencephalogram abnormalities after intra-amniotic prostaglandin F2a. Lancet 1973, 302:1003-1005.

57. Shearman RP, Lyneham RC, Walsh JC, Itzkowic D, Shutt DA: Electroencephalographic changes after intra-amniotic prostaglandin F2alpha and hypertonic saline. Br J Obstet Gynaecol 1975, 82:314-317.

58. Rantala H, Tarkka R, Uhari M: Systematic review of the role of prostaglandins and their synthetase inhibitors with respect to febrile seizures. Epilepsy Res 2001, 46:251-257.

59. Climax J, Sewell RD: Modification of convulsive behaviour and body temperature in mice by intracerebroventricular administration of prostaglandins, arachidonic acid and the soluble acetylsalicylic acid salt lysine acetylsalicylate. Arch Int Pharmacodyn Ther 1981, 250:254-265

60. Bhattacharya SK, Sanyal AK: Inhibition of pentylenetetrazol-induced convulsions in rats by prostaglandin E1: role of brain monoamines. Psychopharmacology (Berl) 1978, 56:235-237.

61. Bhattacharya SK, Sanyal AK: Prostaglandin E1-induced potentiation of the anticonvulsant action of phenobarbitone in the rat. Role of brain monoamines. Prostaglandins Med 1978, 1:159-164.

62. Baik EJ, Kim EJ, Lee SH, Moon C: Cyclooxygenase-2 selective inhibitors aggravate kainic acid induced seizure and neuronal cell death in the hippocampus. Brain Res 1999, 843:118-129.

63. Ellis EF, Wright KF, Wei EP, Kontos HA: Cyclooxygenase products of arachidonic acid metabolism in cat cerebral cortex after experimental concussive brain injury. J Neurochem 1981, 37:892-896.

64. Dhillon HS, Donaldson D, Dempsey RJ, Prasad MR: Regional levels of free fatty acids and Evans blue extravasation after experimental brain injury. J Neurotrauma 1994, 11:405-415.

65. Beaumont A, Marmarou A, Hayasaki K, Barzo P, Fatouros P, Corwin F, Marmarou C, Dunbar J: The permissive nature of blood brain barrier (BBB) opening in edema formation following traumatic brain injury. Acta Neurochir Suppl 2000, 76:125-129.
66. Wang KK, Larner SF, Robinson G, Hayes RL: Neuroprotection targets after traumatic brain injury. Curr Opin Neurol 2006, 19:514-519.

67. Reid WM, Rolfe A, Register D, Levasseur JE, Churn SB, Sun D: Strain-related differences after experimental traumatic brain injury in rats. J Neurotrauma 2010, 27:1243-1253.

68. Tan AA, Quigley A, Smith DC, Hoane MR: Strain differences in response to traumatic brain injury in Long-Evans compared to Sprague-Dawley rats. J Neurotrauma 2009, 26:539-548.

69. Fox GB, LeVasseur RA, Faden Al: Behavioral responses of C57BL/6, FVB/N, and 129/SvEMS mouse strains to traumatic brain injury: implications for gene targeting approaches to neurotrauma. J Neurotrauma 1999, 16:377-389.

70. Steward O, Schauwecker PE, Guth L, Zhang Z, Fujiki M, Inman D, Wrathall J, Kempermann G, Gage FH, Saatman KE, et al: Genetic approaches to neurotrauma research: opportunities and potential pitfalls of murine models. Exp Neurol 1999, 157:19-42.

71. Schauwecker PE, Steward O: Genetic determinants of susceptibility to excitotoxic cell death: implications for gene targeting approaches. Proc Natl Acad Sci USA 1997, 94:4103-4108.

72. Tong $W$, Igarashi T, Ferriero DM, Noble L: Traumatic brain injury in the immature mouse brain: characterization of regional vulnerability. Exp Neurol 2002, 176:105-116.

73. Baskaya MK, Rao AM, Dogan A, Donaldson D, Dempsey RJ: The biphasic opening of the blood-brain barrier in the cortex and hippocampus after traumatic brain injury in rats. Neurosci Lett 1997, 226:33-36.

74. Duvdevani R, Roof RL, Fulop Z, Hoffman SW, Stein DG: Blood-brain barrier breakdown and edema formation following frontal cortical contusion: does hormonal status play a role? J Neurotrauma 1995, 12:65-75.

75. Baskaya MK, Dogan A, Rao AM, Dempsey RJ: Neuroprotective effects of citicoline on brain edema and blood-brain barrier breakdown after traumatic brain injury. J Neurosurg 2000, 92:448-452.

76. Moser VC: Functional assays for neurotoxicity testing. Toxicol Pathol 2011, 39:36-45.

77. Kuhtz-Buschbeck JP, Stolze H, Golge M, Ritz A: Analyses of gait, reaching, and grasping in children after traumatic brain injury. Arch Phys Med Rehabil 2003, 84:424-430.

78. Golge M, Muller M, Dreesmann M, Hoppe B, Wenzelburger R, Kuhtz-Buschbeck JP: Recovery of the precision grip in children after traumatic brain injury. Arch Phys Med Rehabil 2004, 85:1435-1444

79. Toh H, Ichikawa A, Narumiya S: Molecular evolution of receptors for eicosanoids. FEBS Lett 1995, 361:17-21.

80. Singh N, Ma B, Leonardo CC, Ahmad AS, Narumiya S, Doré S: Role of PGE2 EP1 receptor in intracerebral hemorrhage-induced brain injury. Neurotox Res 2013, 24:549-559.

81. Ahmad AS, Zhuang H, Echeverria V, Doré S: Stimulation of prostaglandin EP2 receptors prevents NMDA-induced excitotoxicity. J Neurotrauma 2006, 23:1895-1903.

82. Ahmad AS, Kim YT, Ahmad M, Maruyama T, Doré S: Selective blockade of $\mathrm{PGE}_{2}$ EP1 receptor protects brain against experimental ischemia and excitotoxicity, and hippocampal slice cultures against oxygen-glucose deprivation. Neurotox Res 2008, 14:343-351.

83. Ahmad M, Saleem S, Shah Z, Maruyama T, Narumiya S, Doré S: The PGE EP2 receptor and its selective activation are beneficial against ischemic stroke. Exp Trans/ Stroke Med 2010, 2:12.

84. Ahmad AS, Ahmad M, de Brum-Fernandes AJ, Doré S: Prostaglandin EP4 receptor agonist protects against acute neurotoxicity. Brain Res 2005, 1066:71-77.

doi:10.1186/1742-2094-10-132

Cite this article as: Glushakov et al:: Prostaglandin $\mathrm{F}_{2 a}$ FP receptor antagonist improves outcomes after experimental traumatic brain injury. Journal of Neuroinflammation 2013 10:132. 